\title{
Demographic, procedural and 30-day safety results from the WEB Intra-saccular Therapy Study (WEB-IT)
}

\author{
David Fiorella, ${ }_{1}^{1}$ Andrew Molyneux, ${ }^{2}$ Alexander Coon, ${ }^{3}$ Istvan Szikora, ${ }^{4}$ Isil Saatci, ${ }^{5}$ \\ Feyyaz Baltacioglu, ${ }^{6}$ Ali Sultan, ${ }^{7}$ Adam Arthur, ${ }^{8}$ for the WEB-IT Study Investigators
}

\begin{abstract}
- Additional material is
published online only. To view please visit the journal online (http://dx.doi.org/10.1136/ neurintsurg-2016-012841).
\end{abstract}

1 Department of Neurosurgery, State University of New York at Stony Brook, Stony Brook, New York, USA

${ }^{2}$ Oxford Neurovascular and Neuroradiology Research Unit, Oxford Radcliffe Hospital, Oxford, UK

${ }^{3}$ Johns Hopkins University School of Medicine, The Johns Hopkins Hospital, Baltimore,

Maryland, USA

${ }^{4}$ National Institute of

Neurosciences, Budapest, Hungary

SPrivate Koru Hospital, Ankara, Turkey

${ }^{6}$ Marmara University Faculty of Medicine Pendik Training and Research Hospital, Istanbul, Turkey

${ }^{7}$ Department of Neurosurgery, Brigham and Women's Hospital, Boston, Massachusetts, USA

${ }^{8}$ Semmes-Murphey Neurologic and Spine Institute, University

of Tennessee Department of Neurosurgery, Memphis, Tennessee, USA

\section{Correspondence to} Dr Adam Arthur, SemmesMurphey Neurologic and Spine Institute, University of Tennessee Department of Neurosurgery, 6325 Humphreys Blvd, Memphis, TN 38120, USA; aarthur@semmes-murphey.com

Received 2 November 2016 Accepted 14 December 2016 Published Online First 17 January 2017

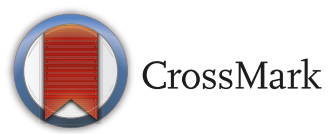

To cite: Fiorella $D_{\text {, }}$

Molyneux A, Coon A, et al.

J Neurolntervent Surg

2017:9:1191-1196.

\section{ABSTRACT}

Introduction The Woven EndoBridge (WEB) represents a novel intrasaccular therapeutic option for the treatment of intracranial wide-necked bifurcation aneurysms (WNBAs). The WEB-IT Study is a pivotal Investigational Device Exemption (IDE) study to determine the safety and effectiveness of the WEB device for the treatment of WNBAs located in the anterior and posterior intracranial circulations. We present the patient demographics, procedural characteristics, and 30-day adverse event data for the US WEB-IT study.

Methods WEB-IT is a prospective multicenter singlearm interventional study conducted at 25 US and 6 international centers. The study enrolled 150 adults with WNBAs of the anterior and posterior intracranial circulations. All patients were intended to receive a WEB device delivered via standard endovascular neurosurgical embolization techniques. The study was conducted under Good Clinical Practices and included independent adjudication effectiveness outcomes and all adverse events.

Results One hundred and fifty patients enrolled at 27 investigational sites underwent attempted treatment with the WEB. Mean age was 59 years (range 29-79) and $110(73.3 \%)$ of the patients were female. Treated aneurysms were located at the basilar apex $(n=59$, $39.3 \%)$, middle cerebral artery bifurcation $(n=45,30 \%)$, anterior communicating artery $(n=40,26.7 \%)$, and internal carotid artery terminus $(n=6,4 \%)$. Average aneurysm size was $6.4 \mathrm{~mm}$ (range 3.6-11.4) with a mean neck size of $4.8 \mathrm{~mm}$ (range 2.0-8.2, mean dome to neck ratio 1.34). Nine patients presented with ruptured aneurysms. Of the enrolled patients, $98.7 \%$ were treated successfully with WEB devices. Mean \pm SD fluoroscopy time was $30.2 \pm 15.7 \mathrm{~min}$. One primary safety event (PSE) (0.7\%) - a delayed parenchymal hemorrhage 22 days after treatment-occurred between the index procedure and 30-day follow-up. In addition to the single PSE, there were seven $(4.7 \%)$ minor ischemic strokes ( 5 resolved without sequelae and 2 had a modified Rankin Scale score of 1 at 30 days), five $(2.7 \%)$ transient ischemic attacks, and two (1.3\%) minor subarachnoid hemorrhages, which did not meet the prospectively established criteria for PSEs.

Conclusions The WEB device can be used to treat WNBAs with a high level of procedural safety and a high degree of technical success.

Trial registration number NCT02191618; Pre-results.

\section{INTRODUCTION}

Wide-necked intracranial aneurysms located at arterial bifurcations (wide-necked bifurcation aneurysms, WNBAs) are an especially difficult subset of intracranial aneurysms to treat, ${ }^{1}$ with increased risks of poor outcome, ${ }^{2}$ stroke, ${ }^{3}$ morbidity, ${ }^{4}$ and mortality. ${ }^{5} 6$

The Woven EndoBridge (WEB) represents a novel intrasaccular therapeutic option for the treatment of intracranial WNBAs. Previous prospective studies have demonstrated favorable safety and efficacy profiles. $^{7-12}$ The WEB-IT Study is a pivotal Investigational Device Exemption (IDE) study to determine the safety and effectiveness of the WEB device for the treatment of WNBAs located in the anterior and posterior intracranial circulations. Data from this study will be used to support a US regulatory submission. The primary purpose of this paper is to summarize the patient demographics, procedural characteristics, and 30-day adverse event (AE) data.

\section{METHODS \\ Study design}

The WEB-IT Study is a prospective multicenter single-arm interventional study conducted at 25 US and 6 international centers. The study enrolled 150 adults with WNBAs of the anterior and posterior intracranial circulations. The study protocol was approved by each center's IRB and all patients submitted written informed consent. The study was conducted under Good Clinical Practices (GCP) and included independent adjudication of all AEs. An independent core laboratory adjudicated effectiveness outcomes. A Data Monitoring Committee conducted study safety reviews.

A detailed set of inclusion and exclusion criteria are included in the online supplementary materials. Required aneurysm characteristics were:

1. Ruptured or unruptured

2. Saccular in shape

3. Located at the basilar apex (BA), middle cerebral artery (MCA) bifurcation, internal carotid artery terminus (ICAt), anterior communicating artery complex (ACom)

4. Dome to neck ratio $\geq 1$

5. Wide-necked intracranial aneurysm with neck size $\geq 4 \mathrm{~mm}$ or dome to neck ratio $<2$

6. Diameter appropriate for treatment with the WEB device per device instructions for use.

Patients with ruptured aneurysms were required to be neurologically stable with a Hunt \& Hess $(\mathrm{H} \& \mathrm{H})$ score of 1 or 2 . Key exclusion criteria included: vascular tortuosity or morphology which could preclude safe access and support during treatment with WEB, and modified Rankin Scale (mRS) score $\geq 2$ at baseline or prior to rupture. 


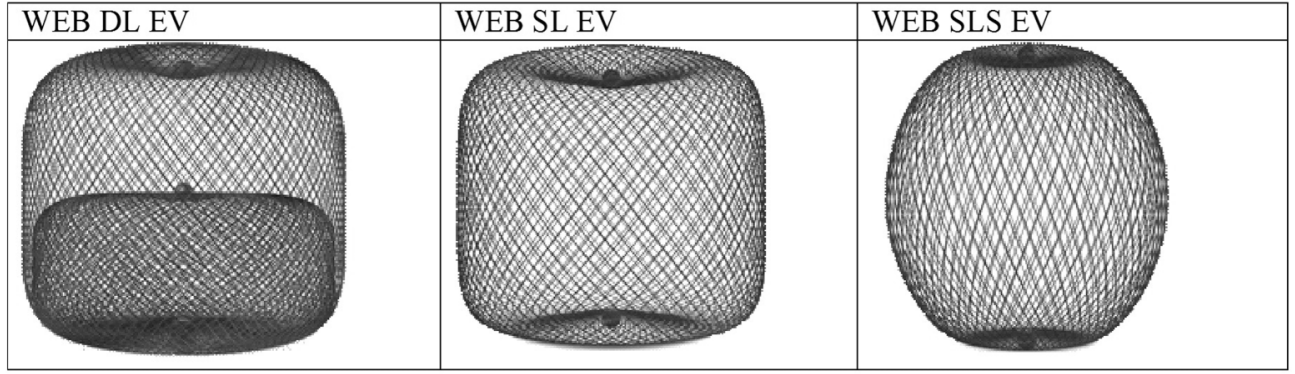

Figure 1 Woven EndoBridge (WEB) devices used in the US WEB-IT Study. Three WEB devices were used: Double Layer (DL), Single Layer (SL), and Single Layer Sphere (SLS). The WEB DL EV is a mesh sphere composed of two layers of braided nitinol/platinum wires. The inner and outer layers of braid are joined by proximal, middle, and distal platinum/iridium markers. The WEB SL EV and WEB SLS EV models are composed of single layers of braided nitinol. The braids are joined at the proximal and distal ends of the device by radiopaque platinum/iridium markers.

\section{Device characteristics}

The WEB Aneurysm Embolization System (Sequent Medical, Aliso Viejo, California, USA) consists of a family of selfexpanding embolization implants developed specifically for the treatment of WNBAs. The WEB Single Layer (SL) and WEB Single Layer Sphere (SLS) models are composed of single layers of braided nitinol/platinum wires. The braids are joined at the proximal and distal ends of the device by radiopaque platinum markers. The WEB Double Layer (DL) is a mesh sphere composed of two layers of braided nitinol wires. The inner and outer layers of braid are joined by proximal, middle, and distal platinum markers (figure 1). The implant is attached to a flexible delivery wire. Detachment of the implant is electrothermal, similar to several other commercially available neurovascular implant delivery systems. WEB devices ranging between $4 \times 3 \mathrm{~mm}$ and $11 \times 9 \mathrm{~mm}$ were available for use within the WEB-IT protocol.

\section{Procedures}

All enrolled patients underwent a standard neuroendovascular procedure (triaxial approach) with the intent of delivering and implanting a WEB device into the index aneurysm. Antiplatelet therapy was recommended based on the publication of Spelle and Liebig. ${ }^{13}$ Patients were considered to be 'enrolled in WEB-IT' with the intention to treat when the WEB device was introduced into the microcatheter during the procedure. Two-dimensional (2D) and three-dimensional (3D) digital subtraction angiography (DSA) was performed to confirm the final device position. Inability to deploy a WEB and the use of implanted adjunctive devices (ie, coils or stents) were considered effectiveness failures. Clinical follow-up was conducted at 30 days, 6 months, 1 year, and annually to 5 years. Follow-up 2D and 3D DSA was performed at 6 months and 1 year.

\section{Study endpoints}

Per protocol safety and effectiveness will be assessed at the 1 year follow-up. The study's primary effectiveness endpoint is the proportion of patients with complete aneurysm occlusion without retreatment, recurrent subarachnoid hemorrhage (SAH), or significant parent artery stenosis ( $>50 \%$ stenosis) at 1 year after treatment. ${ }^{14}$ The study's primary safety endpoint is the proportion of patients with primary safety events (PSEs) which includes death from any non-accidental cause or any major stroke (defined as an ischemic or hemorrhagic stroke resulting in an increase of $\geq 4$ points on the National Institutes of Health Stroke Scale persisting for 7 days after the procedure) within the first 30 days after treatment or major ipsilateral stroke or neurologic death from day 31 to 1 year after treatment.

The study's secondary effectiveness endpoint is the proportion of patients with angiographic aneurysmal recurrence defined as aneurysm growth or recanalization at 1 year after treatment. This proportion will be presented descriptively with the rate and its exact 95\% CI.

\section{Statistical analyses}

This paper reports the study design, patient demographics, procedural characteristics, and 30-day AE information only. No statistics or formal analyses were performed.

\section{RESULTS}

\section{Patient disposition}

One hundred and eighty patients met the initial screening criteria and consented to participate. There were 30 screening failures, the most common reasons being aneurysm characteristics such as size and morphology. One hundred and fifty patients were therefore enrolled at 27 investigational sites. All enrolled patients underwent an interventional procedure with the intention of treating with the WEB device. These data are included in the present 30-day safety analysis (figure 2).

\section{Patient demographic and baseline characteristics}

All patients were enrolled between August 2014 and March 2016. The baseline characteristics are summarized in table 1 . Baseline aneurysm characteristics are shown in table 2.

Mean age at treatment was $59 \pm 0.83$ years (range 29_ 79 years); $73.3 \%$ were female. Nine patients presented with ruptured aneurysms; six were $\mathrm{H} \& \mathrm{H} 1$ and three were $\mathrm{H} \& \mathrm{H} 2$.

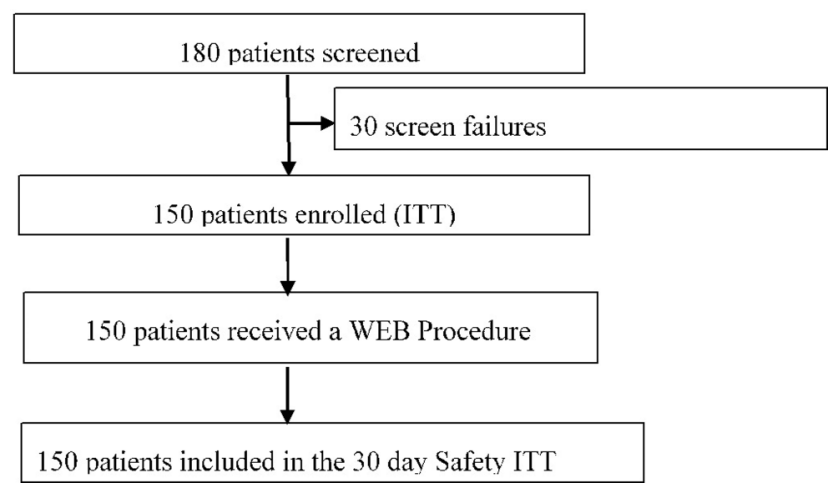

Figure 2 Study screening and enrollment. 
Table 1 Baseline characteristics $(\mathrm{N}=150)$

\begin{tabular}{|c|c|}
\hline Baseline characteristics & \\
\hline \multicolumn{2}{|l|}{ Age at procedure (years) } \\
\hline Mean \pm SE & $59.0 \pm 0.83$ \\
\hline Range & $29-79$ \\
\hline \multicolumn{2}{|l|}{ Age group } \\
\hline $18-35$ & $4(2.7 \%)$ \\
\hline $36-50$ & $20(13.3 \%)$ \\
\hline $51-64$ & $75(50.0 \%)$ \\
\hline $65-75$ & $49(32.7 \%)$ \\
\hline $76+$ & $2(1.3 \%)$ \\
\hline \multicolumn{2}{|l|}{ Gender } \\
\hline Women & $110(73.3 \%)$ \\
\hline Men & $40(26.7 \%)$ \\
\hline \multicolumn{2}{|l|}{ Hunt \& Hess grade } \\
\hline 0 & $141(94.0 \%)$ \\
\hline 1 & $6(4.0 \%)$ \\
\hline 2 & $3(2.0 \%)$ \\
\hline \multicolumn{2}{|l|}{ Modified Rankin score } \\
\hline 0 & $119(79.3 \%)$ \\
\hline 1 & $31(20.7 \%)$ \\
\hline \multicolumn{2}{|l|}{ Smoking status } \\
\hline Smoker & $98(65.3 \%)$ \\
\hline Current & $64(42.7 \%)$ \\
\hline Past & $34(22.7 \%)$ \\
\hline Non-smokers & $52(34.7 \%)$ \\
\hline \multicolumn{2}{|l|}{ US/OUS } \\
\hline US & $116(77.3 \%)$ \\
\hline ous & $34(22.7)$ \\
\hline \multicolumn{2}{|l|}{ Pre-existing conditions } \\
\hline Arrhythmia & $7(4.7 \%)$ \\
\hline Coronary artery disease & $21(14.0 \%)$ \\
\hline Heart failure & $3(2.0 \%)$ \\
\hline Hypertension & $96(64.0 \%)$ \\
\hline Peripheral vascular disease & $5(3.3 \%)$ \\
\hline Valve disease/dysfunction & $4(2.7 \%)$ \\
\hline Diabetes mellitus & $10(6.7 \%)$ \\
\hline Hypercholesterolemia & $16(10.7 \%)$ \\
\hline Hyperlipidemia & $38(25.3 \%)$ \\
\hline Hypertriglyceridemia & $0(0.0 \%)$ \\
\hline Headaches/migraines & $57(38.0 \%)$ \\
\hline Neuropathy & $12(8.0 \%)$ \\
\hline Seizures & $6(4.0 \%)$ \\
\hline \multicolumn{2}{|l|}{ Prior CVA } \\
\hline Ischemic stroke & $18(12.0 \%)$ \\
\hline Hemorrhagic stroke & $10(6.7 \%)$ \\
\hline \multicolumn{2}{|l|}{ Prior TIA } \\
\hline Yes & $9(6.0 \%)$ \\
\hline No & $138(92.0 \%)$ \\
\hline Unknown & $3(2.0 \%)$ \\
\hline \multicolumn{2}{|l|}{ Race } \\
\hline White & $98(65.3 \%)$ \\
\hline Black or African American & $14(9.3 \%)$ \\
\hline Asian & $4(2.7 \%)$ \\
\hline Not available & $34(22.7 \%)$ \\
\hline \multicolumn{2}{|l|}{ Ethnicity } \\
\hline Not Hispanic or Latino & $114(76 \%)$ \\
\hline Hispanic or Latino & $2(1.3 \%)$ \\
\hline Not available & $34(22.7 \%)$ \\
\hline
\end{tabular}

CVA, cardiovascular accident; OUS, outside of the United States of America; TIA, transient ischemic attack.
Table 2 Aneurysm characteristics $(\mathrm{N}=150)$

\begin{tabular}{ll}
\hline Aneurysm characteristics & \\
\hline Aneurysm status & $9(6.0 \%)$ \\
Ruptured & $141(94.0 \%)$ \\
Unruptured & \\
Aneurysm location & $59(39.3 \%)$ \\
BA terminus & $6(4.0 \%)$ \\
ICA terminus & $45(30.0 \%)$ \\
MCA bifurcation & $40(26.7 \%)$ \\
ACom & \\
Dome width (mm) & 6.4 \\
Mean & 6.3 \\
Median & $3.6-11.4$ \\
Range & \\
Dome height (mm) & 6.1 \\
Mean & 6.0 \\
Median & $3.1-10.3$ \\
Range & \\
Aneurysm neck size (mm) & 4.8 \\
Mean & 4.7 \\
Median & $2.0-8.2$ \\
Range & \\
Dome to neck ratio & 1.4 \\
Mean & 1.3 \\
Median & $1.0-2.0$ \\
Range & \\
\hline ACom, anterior communicating artery; BA, basilar apex; ICA, internal carotid artery; \\
MCA, middle cerebral artery.
\end{tabular}

Ninety-eight $(65.3 \%)$ were current or past smokers. One hundred and sixteen patients (77.3\%) were enrolled at US sites while $34(22.7 \%)$ were enrolled at international sites. The predominant pre-existing conditions included hypertension in $64 \%$, a history of headaches/migraines in $38 \%$, and hyperlipidemia in $25.3 \%$. Eighteen $(12.0 \%)$ had a history of ischemic stroke, $10(6.7 \%)$ had a history of hemorrhagic stroke, and nine (6.0\%) had a history of transient ischemic attack (TIA).

With respect to aneurysm characteristics (table 2), 91 (60.7\%) were located in the anterior circulation and $59(39.3 \%)$ in the posterior circulation. The mean dome width was $6.4 \mathrm{~mm}$ (range 3.6-11.4), mean dome height was $6.1 \mathrm{~mm}$ (range 3.1-10.3), mean neck size was $4.8 \mathrm{~mm}$ (range 2.0-8.2), and mean dome to neck ratio was 1.3 (range 1.0-2.0).

\section{Procedural and device data}

All 150 patients underwent attempted endovascular treatment with the WEB. A WEB device was successfully implanted in 148 (technical success $=98.7 \%$ ). In two patients WEB treatment was unsuccessful; one due to anatomic tortuosity and one due to improper device size availability. Adjunctive stenting was performed in two cases where the WEB appeared to impinge upon the parent artery or adjacent branch. Adjunctive balloons were used to assist WEB positioning in five cases.

Table 3 presents key procedural data. For the 148 patients implanted, WEB procedure times averaged $20.1 \pm 21.2$ min with a range of 3-215 min. The median WEB time (time from insertion of WEB to removal of WEB delivery system) was $14 \mathrm{~min}$. Procedural fluoroscopy times averaged $30.2 \pm 15.7 \mathrm{~min}$ and radiation doses averaged $2750 \pm 2577 \mathrm{mGy}$. 
Table 3 WEB times and radiation exposure data

\begin{tabular}{ll}
\hline Parameter & \\
\hline WEB times* (min) & $20.1 \pm 21.2(148)$ \\
Mean \pm SD (N) & 14 \\
Median & 3,215 \\
Min, max & \\
Fluoroscopy times (total, min) & $30.2 \pm 15.7$ (146) \\
Mean \pm SD (N) & 26.8 \\
Median & $8.9,82$ \\
Min, max & \\
Fluoroscopy doses (total, mGy) & $2750 \pm 2577(148)$ \\
Mean $\pm S D(N)$ & 2281 \\
Median & 79,22746 \\
Min, max & \\
\hline *Time from insertion of WEB to removal of delivery system following detachment. \\
WEB, Woven EndoBridge.
\end{tabular}

Table 4 provides the locations and device configurations. The most common implant location in the study was the basilar artery (39.2\%), followed by the MCA (30.4\%), the ACom (26.4\%), and the ICA terminus (4.31\%). Nineteen $(12.8 \%)$ WEB DL, 107 (72.3\%) WEB SL, and 22 (14.9\%) WEB SLS were implanted. The most common device diameter implanted was $7 \mathrm{~mm}(\mathrm{n}=41)$, followed by $8 \mathrm{~mm}(\mathrm{~N}=31), 6 \mathrm{~mm}$ and $5 \mathrm{~mm}$ $(\mathrm{N}=28$ each $)$.

\section{Technical events}

There were 12 reported technical events involving the deployment or detachment of the WEB device. These included device failed to open or appeared twisted on deployment $(n=3)$, WEB detachment system failure $(n=3)$, kinked pusher $(n=2)$, multiple attempts required for detachment $(\mathrm{n}=2)$, inability to resheath $(n=1)$, and WEB appeared damaged $(n=1)$. There were no AEs or patient sequelae as a result of any malfunction or failure and a WEB was successfully implanted in all of these cases.

\section{Safety}

Primary safety events (PSEs)

There was one PSE $(0.7 \%)$ in the interval between the index procedure and post-procedure day 30 . The event, a delayed ipsilateral parenchymal hemorrhage unrelated to the treated aneurysm, occurred on post-procedure day 22. The event was adjudicated as a major stroke, most likely related to antiplatelet medication and underlying cerebrovascular disease. At last follow-up the patient's mRS score was 4 .

Table 4 WEB implant locations by device configuration

\begin{tabular}{lccll}
\hline $\begin{array}{l}\text { WEB implant } \\
\text { locations }\end{array}$ & DL & SL & SLS & Total \\
\hline ACom & 4 & 28 & 7 & $39(26.4 \%)$ \\
Basilar & 10 & 42 & 6 & $58(39.2 \%)$ \\
ICAt & 1 & 1 & 4 & $6(4.1 \%)$ \\
MCA & 4 & 36 & 5 & $45(30.4 \%)$ \\
Total & $19(12.8 \%)$ & $107(72.3 \%)$ & $22(14.9 \%)$ & 148 \\
\hline
\end{tabular}

ACom, anterior communicating artery; DL, Double Layer; ICAt, internal carotid artery terminus; MCA, middle cerebral artery; SL, Single Layer; SLS, Single Layer Sphere; WEB, Woven EndoBridge.
Additional safety outcomes

There were no deaths and no unanticipated adverse device effects (UADEs). There were seven (4.7\%) minor ischemic strokes; five resolved without sequelae and two were mRS 1 at 30 days. Of these, one was device-related, four were procedure-related, and two were unrelated to either the device or the procedure. There were five $(2.7 \%)$ TIAs. There were three $(2 \%)$ cases of arterial thrombosis in the parent or branch vessels near the WEB device. All were device-related and all resolved without sequelae. Of these, two vessels were opened with stents and the third responded to an eptifibatide infusion.

There were two cases of intraprocedural SAH. In one case, contrast extravasation was noted intraprocedurally and, in the second, contrast extravasation was noted on CT after the procedure. In both cases the WEB device was successfully delivered and both patients were discharged without neurological symptoms.

Overall, there were 136 AEs which occurred in 65 patients, of which 24 were categorized as serious. Nine were adjudicated as device-related and 68 were procedure-related. Other common events in the 30-day period included headache $(n=21$, $15.4 \%)$, nausea $(n=7,5.1 \%)$, and vessel puncture site pain $(\mathrm{n}=5,3.7 \%)$. Of all 136 AEs, 125 resolved without sequelae, 8 remain ongoing, and 3 incurred sequelae.

\section{Morbidity and mRS status}

One patient $(0.7 \%)$ experienced a major stroke during the 30 day peri-procedural period-as described above-and had a mRS score of 4 at 30 days. Eight patients had increases in the $\mathrm{mRS}$ score of 1 point; four of these were due to minor ischemic strokes, one was due to residual post-procedure headache and shoulder pain, and one was interpreted as inter-rater variability as no events occurred.

\section{Ruptured cases}

Of the nine patients who presented with ruptured aneurysms, seven had 15 AEs; 14 of these were non-serious and 1, an incidentally discovered spinal stenosis, was serious. There was no morbidity and all events resolved without sequelae. Only one event, a procedural arterial thrombosis, was both serious and device-related. This patient underwent intra-procedural stenting of a thrombosed branch artery adjacent to the WEB and recovered uneventfully. Two procedure-related AEs were associated with a hematoma or hemorrhage at the femoral puncture site. The most common AEs were electrolyte imbalance (three events in two patients) and headache (two events in two patients).

\section{DISCUSSION}

This study shows that (1) the treatment of appropriately selected WNBAs is feasible with the WEB device in most cases; and (2) the treatment of WNBAs with the WEB device may be performed with a high level of safety.

WNBAs are among the most challenging aneurysms encountered for endovascular treatment. Their treatment frequently requires craniotomy for clipping of the aneurysm or the use of one or more temporary (ie, a balloon catheter) or permanently (ie, intravascular stent) implanted adjunctive devices. Such complex treatment strategies are technically demanding, time intensive, require multiple catheter manipulations, and are likely to be associated with higher complication rates than more straightforward coil embolization procedures. Moreover, complete occlusion of WNBAs is often difficult to achieve with conventional endovascular coiling and the occlusion achieved with 
coils may not be durable. For this reason, better endovascular treatment options are needed. ${ }^{15}$

Intrasaccular flow disruption conceptually addresses many of the shortcomings of predicate endovascular technologies for the treatment of WNBA. The WEB allows for the single-step treatment of WNBAs in a procedure which is technically more similar to straightforward coil embolization than stent-assisted coiling or balloon remodeling. ${ }^{16-20}$ Once implanted, the WEB provides considerably greater metal surface area coverage at the aneurysm neck than standard intravascular flow diverters, with coverage increasing centripetally, ranging from $55 \%$ to $100 \%$ with the WEB compared with 30-35\% with standard commercially available intravascular flow diverters. ${ }^{21} 22$ This improved coverage at the aneurysm neck has the potential to provide greater levels of flow disruption within the aneurysm as well as a more robust physical lattice for neointimal growth. ${ }^{23}$ These physical characteristics might have favorable effects on both the rates of complete occlusion and the durability of the occlusions achieved. The final results of the US WEB-IT trial will provide further data regarding the efficacy and durability of WEB treatment.

\section{Technical success rate}

In appropriately selected aneurysms, WEB embolization was possible in nearly $100 \%$ of cases during the WEB-IT trial. Treatment failed in only two cases, one related to tortuous anatomy and the other related to the unavailability of an appropriately sized device. It is important to underscore the role of case selection in achieving these levels of technical success. De-identified images of all potential WEB-IT patients were screened according to the WEB-IT inclusion criteria and approved by study physicians prior to enrollment. In addition, most cases were proctored by more experienced WEB users. Finally, because the study was conducted primarily by WEB-naive US investigators with no roll-in cases, numerous aneurysms were replicated and the treatment practiced prior to the actual attempted treatment. As such, while the technical success rate was extremely high, this rate may not be reflective of the entire population of WNBAs encountered in clinical practice.

\section{Procedure times}

The technically straightforward nature of many WEB cases was reflected by the brevity of the overall case times and total fluoroscopic times. Fluoroscopy times for the cases averaged approximately $30 \mathrm{~min}$, and nearly one-third of the cases $(n=49$; $32.7 \%$ ) were completed using less than $20 \mathrm{~min}$ of total fluoroscopic time. The WEB treatment procedure, as a single step technique, eliminates many of the manipulations required for typical WNBA treatments. In a typical Y-stent assisted coiling case, both limbs of the bifurcation must be catheterized and stented, followed by catheterization of the aneurysm and the delivery and detachment of multiple embolization coils. For similar cases treated with WEB, the aneurysm is catheterized, a single device is delivered, assessed angiographically, and then detached. Provided that the original device selected is of an appropriate configuration (SL or SLS) and size, these cases can be completed rapidly and with a minimal number of steps and intracranial manipulations. ${ }^{24} 25$

While more efficient from the standpoint of the actual case performance, it should be noted that the anatomical analysis of the aneurysm and selection of the optimal device configuration and size require a considerable commitment of time and cognitive effort prior to the case. In the present study, high quality angiographic imaging was essential to optimal case planning. Without detailed preoperative imaging and planning, procedure times would certainly have been higher.

\section{Safety of WEB-IT procedures relative to other techniques}

Consistent with previous studies, the rates of major procedural and peri-procedural complications associated with WEB treatment were low, with only a single major peri-procedural stroke observed during the study $(0.7 \%) .{ }^{9}{ }^{12}$ Moreover, this complication (a delayed lobar parenchymal hemorrhage occurring 22 days after treatment) is of uncertain relation to the actual index procedure. At the same time, rates of less severe periprocedural ischemic events (7 minor strokes, 4.7\%) and hemorrhagic events (2 SAHs, 1.4\%) were similar to those reported in other studies of endovascular aneurysm treatment. Of note, only two of these patients with neurological events which did not reach the PSE criteria experienced increases in their mRS
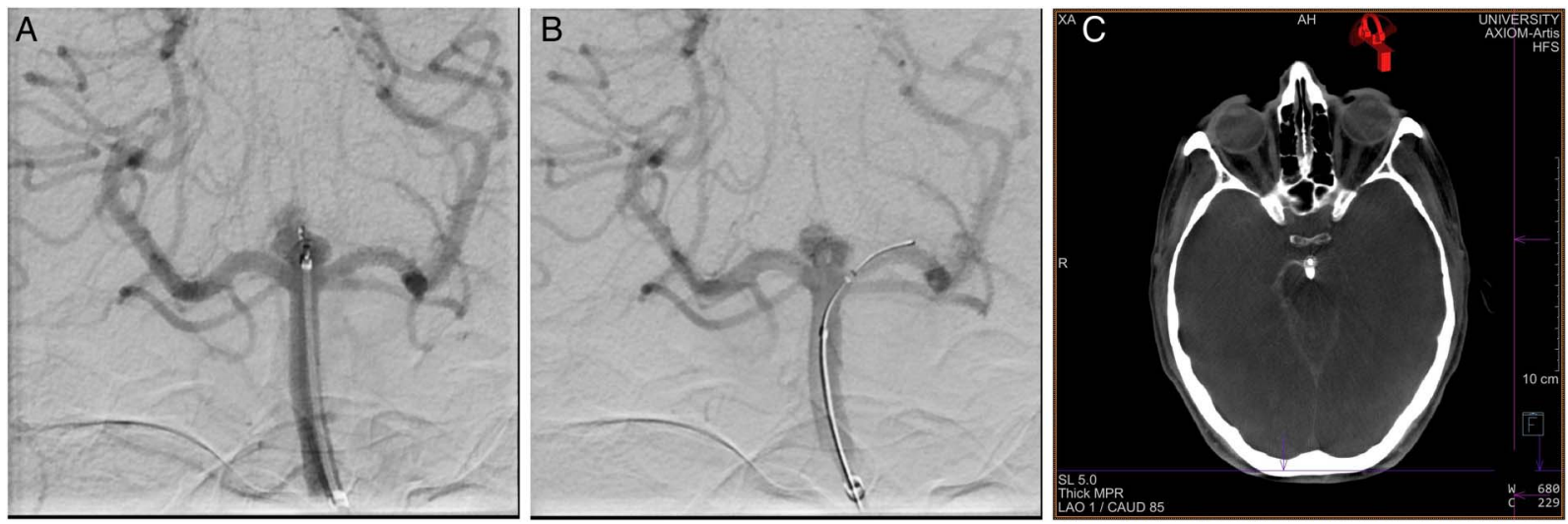

Figure 3 Procedural perforation with the Woven EndoBridge (WEB) device. A woman with an unruptured basilar apex aneurysm presented for treatment with WEB. Immediately following detachment of the Double Layer (DL) device, the microcatheter was advanced distally into the proximal aspect of the aneurysm. Angiography following the detachment demonstrated a small amount of active contrast extravasation from the aneurysm dome (A). Heparinization was reversed with protamine and a Hyperform $4 \times 7 \mathrm{~mm}$ balloon (Medtronic; Irvine, California, USA) was transiently inflated within the mid-basilar artery. Angiography was repeated, demonstrating resolution of the extravasation, despite residual filling of the aneurysm (B). Cone beam CT performed at the conclusion of the treatment showed a small amount of contrast extravasation within the interpeduncular cistern $(C)$. The patient experienced no neurological sequelae from the transient extravasation. 
score (from 0 to 1 ) at 30 -day follow-up; the others were at baseline at the 30-day assessment.

The two peri-procedural SAHs resulted in minimal symptoms despite both patients being treated with dual antiplatelet therapy at the time of their hemorrhages. This reflects the rapidity with which the WEB device is able to achieve hemostasis and aneurysm protection, even in the setting of intraprocedural hemorrhage. In one case, active extravasation was seen after the microcatheter migrated forward following WEB detachment. The observed extravasation was treated with protamine and transient inflation of a balloon within the parent artery. The extravasation ceased within minutes and the patient awoke from the procedure with no neurological symptoms (figure 3). In the second case, no extravasation was observed during the procedure but, rather, a small amount of contrast distributed within the ipsilateral subarachnoid space was noted on a postprocedure CT of the head.

When the WEB-IT data are considered together with data from WEBCAST, WEBCAST2, and the French Observatory Studies, a total of 317 patients with WNBAs have been treated with WEB devices within the context of prospective, externally adjudicated and monitored GCP studies. The combined periprocedural safety data for these four studies yield an overall morbidity rate of $2 \%$ (5/317 patients) with no deaths. ${ }^{8} \quad 11 \quad 12$ These rates are significantly lower than those reported previously in the treatment of WNBAs. ${ }^{25}$

\section{CONCLUSION}

In appropriately selected WNBAs, treatment with the WEB device is both technically feasible and safe. The 30-day safety data compare favorably with other surgical and endovascular treatments for similar aneurysms. ${ }^{26-28}$ These initial short-term safety results from the US WEB-IT trial are also consistent with observations made in prior European prospective GCP trials of the WEB device.

Contributors All named authors contributed substantially to the work described by actively participating in the study and the generation of the data and providing editorial evaluation of the manuscript.

Funding Sequent Medical Inc.

Competing interests The primary investigators for the WEB IT trial received institutional salary support for study related activities. Investigators in the WEB IT trial also received payment for proctoring cases within the context of the trial.

Ethics approval US FDA, local IRBs.

Provenance and peer review Not commissioned; externally peer reviewed.

\section{REFERENCES}

1 Fargen KM, Velat GJ, Lawson MF, et al. The stent anchor technique for distal access through a large or giant aneurysm. J Neurointerv Surg 2013;5:e24.

2 Wiebers DO, Whisnant JP, Huston J III, et al. Unruptured intracranial aneurysms: natural history, clinical outcome, and risks of surgical and endovascular treatment. Lancet 2003;362:103-10.

3 Birknes JK, Hwang SK, Pandey AS, et al. Feasibility and limitations of endovascular coil embolization of anterior communicating artery aneurysms: morphological considerations. Neurosurgery 2006;59:43-52.

4 Lusseveld E, Brilstra EH, Nijssen PC, et al. Endovascular coiling versus neurosurgical clipping in patients with a ruptured basilar tip aneurysm. J Neurol Neurosurg Psychiatry 2002;73:591-3.
5 Spetzler RF, McDougall CG, Albuquerque FC, et al. The Barrow ruptured aneurysm trial: 3-year results. J Neurosurg 2013;119:146-57.

6 Spetzler RF, McDougall CG, Zabramski JM, et al. The Barrow ruptured aneurysm trial: 6-year results. J Neurosurg 2015;123:609-17.

7 Liebig T, Kabbasch C, Strasilla C, et al. Intrasaccular flow disruption in acutely ruptured aneurysms: a multicenter retrospective review of the use of the WEB. AJNR Am J Neuroradiol 2015;36:1721-7.

8 Pierot $L$, Arthur A, Spelle $L$, et al. Current evaluation of the safety and efficacy of aneurysm treatment with the WEB device. AJNR Am J Neuroradiol 2016;37:586-7.

9 Pierot L, Costalat V, Moret J, et al. Safety and efficacy of aneurysm treatment with WEB: results of the WEBCAST study. J Neurosurg 2016;124:1250-6.

10 Pierot L, Klisch J, Liebig T, et al. WEB-DL endovascular treatment of wide-neck bifurcation aneurysms: long-term results in a European series. AJNR Am J Neuroradiol 2015;36:2314-19.

11 Pierot L, Moret J, Turjman F, et al. Web treatment of intracranial aneurysms: clinical and anatomic results in the French observatory. AJNR Am J Neuroradiol 2016;37:655-9.

12 Pierot L, Spelle L, Molyneux A, et al. WEBCAST and French Observatory Investigators. Clinical and anatomical follow-up in patients with aneurysms treated with the web device: 1-year follow-up report in the cumulated population of 2 prospective, multicenter series (WEBCAST and French observatory). Neurosurgery 2016;78:133-41.

13 Spelle L, Liebig T. Letter to the editor. Neuroradiol J 2014;27:369.

14 Fiorella D, Arthur A, Byrne J, et al. Interobserver variability in the assessment of aneurysm occlusion with the web aneurysm embolization system. J Neurointerv Surg 2015;7:591-5.

15 Bechan RS, Sprengers ME, Majoie CB, et al. Stent-assisted coil embolization of intracranial aneurysms: complications in acutely ruptured versus unruptured aneurysms. AJNR Am J Neuroradiol 2016;37:502-7.

16 Fiorella D, Woo HH. Balloon assisted treatment of intracranial aneurysms: the conglomerate coil mass technique. J Neurointerv Surg 2009;1:121-31.

17 Fiorella $D$, Albuquerque FC, Deshmukh VR, et al. Usefulness of the Neuroform stent for the treatment of cerebral aneurysms: results at initial (3-6-mo) follow-up. Neurosurgery 2005;56:1191-201; discussion 1201-2.

18 Fiorella D, Albuquerque FC, Deshmukh VR, et al. In-stent stenosis as a delayed complication of Neuroform stent-supported coil embolization of an incidental carotid terminus aneurysm. AJNR Am J Neuroradiol 2004;25:1764-7.

19 Fiorella D, Albuquerque FC, Deshmukh VR, et al. Endovascular reconstruction with the Neuroform stent as monotherapy for the treatment of uncoilable intradural pseudoaneurysms. Neurosurgery 2006;59:291-300.

20 Fiorella $\mathrm{D}$, Albuquerque $\mathrm{FC}$, Han $\mathrm{P}$, et al. Preliminary experience using the Neuroform stent for the treatment of cerebral aneurysms. Neurosurgery. 2004; 54:6-16; discussion 16-17.

21 Fiorella D, Kelly ME, Albuquerque FC, et al. Curative reconstruction of a giant midbasilar trunk aneurysm with the Pipeline embolization device. Neurosurgery. 2009;64:212-17.

22 Fiorella D, Lylyk P, Szikora I, et al. Curative cerebrovascular reconstruction with the Pipeline embolization device: the emergence of definitive endovascular therapy for intracranial aneurysms. J Neurointerv Surg 2009;1:56-65.

23 Fiorella D. Pipeline in clinical practice in 2011. Neuroradiology 2012;54:277-8.

24 Clajus C, Strasilla C, Fiebig T, et al. Initial and mid-term results from 108 consecutive patients with cerebral aneurysms treated with the WEB device. J Neurointerv Surg 2016. doi: 10.1136/neurintsurg-2016-012276. [Epub ahead of print 13 Apr 2016].

25 Klisch J, Sychra V, Strasilla C, et al. The Woven EndoBridge cerebral aneurysm embolization device (WEB II): initial clinical experience. Neuroradiology 2011:53:599-607.

26 Hetts SW, Turk A, English JD, et al. Stent-assisted coiling versus coiling alone in unruptured intracranial aneurysms in the matrix and platinum science trial: safety, efficacy, and mid-term outcomes. AJNR Am J Neuroradiol 2014;35:698-705.

27 Cognard C, Pierot L, Anxionnat R, et al. Results of embolization used as the first treatment choice in a consecutive nonselected population of ruptured aneurysms: clinical results of the Clarity GDC study. Neurosurgery. 2011;69:837-41; discussion 842.

28 Pierot L, Spelle L, Vitry F, et al. Immediate clinical outcome of patients harboring unruptured intracranial aneurysms treated by endovascular approach: Results of the ATENA study. Stroke 2008;39:2497-504. 